\title{
Effectiveness of Educational Intervention on ECG Monitoring and Interpretation among Nursing Students
}

\author{
Mrs.Melita Sheilini ${ }^{1}$, Dr. Elsa Sanatombi Devi ${ }^{2}$ \\ ${ }^{1}$ Asst.Professor-senior scale, Department of Medical Surgical Nursing, Manipal College of Nursing Manipal, \\ ${ }^{2}$ Professor, Department of Medical Surgical Nursing, Manipal College of Nursing Manipal, Manipal University
}

\begin{abstract}
One of the important critical care nursing skills is monitoring ECG. It can provide evidence to support a diagnosis, and it is crucial for patient management by helping in diagnosing the abnormal cardiac rhythm.In potentially life threatening situations, the nurse is expected to interpret the rhythm accurately and respond appropriately. To do this the nurse must be well educated in rhythm interpretation. The present study was carried out with the objectives to assess the knowledge of nursing students in ECG monitoring and interpretation, to assess the skill in interpreting ECG among nursing students, to determine the effectiveness of teaching program on ECG monitoring and interpretation, to find out the association between knowledge on ECG monitoring and interpretation andvariables,to find out the association between the skill in interpreting ECG and the variables and to determine the relationship between knowledge and skill of nursing students in ECG monitoring and interpretation.The research approach used for this study was evaluative research. One group pretestposttest design was adopted. About $40 \mathrm{MSc}$ Nursing $1^{\text {st }}$ year students were selected using convenient sampling technique. The data collection instruments were: Demographic Proforma,Strucutred knowledge questionnaire on ECG monitoring and interpretation and Tool to assess skill in ECG interpretation. Teaching content on ECG monitoring and interpretation was prepared on the basis of review of literature and in consultation with experts. Content validity of the teaching content was established by giving it to nine experts in different fields and modifications were made according to experts' suggestions. The tools were pretested before use among 5 PBBSc(N) students.Reliability coefficient of Structured knowledge questionnaire was found out by using Split half technique and the tool was found reliable $(r=0.90)$. Test retest method was used to find out the reliability coefficient of skill tool and it was found reliable $(r=0.80)$.Descriptive and inferential statistics were used to analyze the data. The significant findings of the study were: Majority 31(77.5\%) of the students had ICU experience and majority 19(47.5\%) and 18(45\%) had work experience of < lyear and > 1-3 years respectively. It was found that the majority 22(55\%) had good knowledge on ECG monitoring and interpretation and only one student had poor knowledge whereas during post test it was found that majority $26(65 \%)$ had good knowledge and no one had poor knowledge.The results also revealed that majority $23(57.5 \%)$ hhad poor skill in interpreting ECG during pretest whereas majority 36(90\%) had good skill in interpreting ECG and no one belonged to the category of poor skill.Statistical analysis showed there was a no significant increase in knowledge scores $\left(t_{(39)}=1.302, p>0.05\right)$ but the skill scores had significant improvement $\left.t_{(39)}=13.181, p<0.05\right)$ after the teaching program. It was found that there was significant association between the knowledge of nursing students on ECG monitoring and interpretationand areas of work experience $\left(\chi^{2}=12.10, p=0.001\right)$ and years of work experience $\left(\chi^{2}=29.00, p<0.001\right)$. Also there was significant association between the skill of nursing students in ECG interpretation and areas of work experience $\left(\chi^{2}\right.$ $=12.10, p=0.001)$ and years of work experience $\left(\chi^{2}=29.00, p<0.001\right)$.
\end{abstract}

Keywords:Effectiveness,knowledge,skill, ECG, nursing students,

\section{Introduction}

Cardiovascular disease (CVD) is the leading cause of death in many regions worldwide, accounting for nearly one third of global deaths. ${ }^{1}$ Every patient, nurse and care facility is different. So providing the right nursing care for critically ill patients is not simply a matter of applying standard nurse-to-patient ratios. The skill of the nurse,

the complexity of the patient's needs and the physical environment of care will all influence nursing requirements. ${ }^{2}$ Nursing has progressed from ancient era to the dawn of modern nursing with the coming of Florence Nightingale and now to $21^{\text {st }}$ century. The progress has been along with the socio-economic cultural changes all over the world, bringing along with it tremendous advancement in science and technology. Today's professional nurse is no more only in the role of carrying out doctor's order. Today's nurse is expected to make independent decisions in the day-to-day health care activities. This decision-making ability comes from having relevant knowledge, appropriate attitude and expert skills about health care measures, which together may be referred to as health care competency. Also precision in decision making about a health related activity depends on elaborate health assessment, analysis of the health parameters and identifying specific health problems and 
needs. One of such important health parameters is ECG.Therefore it is essential that nurses are able to analyze ECG reading accurately, in order to make independent decisions in health care and to assist in therapeutic process.

\section{Methods}

The first year MSC Nursing students 40 were selected for the study conveniently. The research approach used for this study was evaluative research. One group pretestposttest design was adopted. The data collection instruments were: Demographic Proforma,Strucutred knowledge questionnaire on ECG monitoring and interpretation and Tool to assess skill in ECG interpretation. The Knowledge quaestionnaire had 30 items and the scores were arbitrarily classified as poor (0-10), average (11-20) and good(21-30) knowledge. The skill tool consisted of 10 ECG strips of various arrhythmias with 7 questions for each ECG strip. The items were based on areas like characteristics of ECG, interpretation of ECG given and treatment recommended for that particular arrhythmia. For each correct answer from (items 2-5) a score of one was given and for (items 1,6 and 7) a score of 2 marks was given. Wrong answer was given zero score. Total score of items in each ECG strip was 10 .The highest possible score of the tool was100.The skill score were arbitrarily classified as good (68100), average (34-67) and poor (0-33).Teaching content on ECG monitoring and interpretation was prepared on the basis of review of literature and in consultation with experts. Content validity of the teaching content was established by giving it to nine experts in different fields and modifications were made according to experts' suggestions. The tools were pretested before use. Reliability of Structured knowledge questionnaire was found out by using Split half technique and the tool was found reliable $(\mathrm{r}=0.90)$. Test retest method was used to find out the reliability of skill tool and it was found reliable $(\mathrm{r}=0.80)$. The ethical clearance was obtained from the Institutional Ethical Committee(IEC) before proceeding for data collection. Written informed consent was obtained from the participants before collecting the data. The teaching was done on the same day of pretest. The tools were self administered. The post test was conducted one month after the intervention.During that one month everybody had the ICU experience as part of their Advanced Nursing practice clinical posting.

\section{Results And Discussion}

Descriptive and inferential statistics were used to analyze the data. The findings of the study in Table 1 show that majority $31(77.5 \%)$ of the students had ICU experience and majority $19(47.5 \%)$ and $18(45 \%)$ had work experience of < 1year and > 1-3 years respectively. The data presented in Table 2 show that majority $22(55 \%)$ had good knowledge on ECG monitoring and interpretation and only one student had poor knowledge whereas during post-test it was found that majority $26(65 \%)$ had good knowledge and no one had poor knowledge. The results of Table 3 revealed that majority 23(57.5\%) had poor skill in interpreting ECG during pretest whereas majority $36(90 \%)$ had good skill in interpreting ECG and no one belonged to the category of poor skill. Statistical analysis presented in Table 4 showed that though there was some improvement in the knowledge scores after the teaching program but statistically it was not found significant $\left(\mathrm{t}_{(39)}=1.302\right.$, $\mathrm{p}>0.05)$.Table 5 showed that the skill scores had significant improvement $\left(\mathrm{t}_{(39)}=13.181, \mathrm{p}<0.05\right)$ after the intervention.Areawise analysis of the skill presented in Table 6 show that after the intervention there was improvement in the area of interpreting arrhythmias from $8(20 \%)$ to $36(90 \%)$ and in the area of identifying the components of ECG from 6(15\%) to 22(55\%).

The above findings are supported by the study conducted by Lamb MJ and Henderson MC after the two teaching methods [Assisted self-directed learning (ASD) and traditional lecture methods (TLM)] designed foracquiring competency in electrocardiogram interpretation, the EKG post-test scores for the experimental group (ASD, M=81) and the control group (TLM, M=71) were significantly different, indicating that both the teaching methods were effective in improving the competency of critical care nurses' competency in ECG monitoring and interpretation. ${ }^{3}$

The findings of the present study supports the study conducted by Sheilini M in 2007 where there was a significant increase in the knowledge $\mathrm{t}=9.35$ and skill $\mathrm{t}=4.78\left[\mathrm{t}_{(29)}=2.04, \mathrm{p}<0.05\right]$ of critical care staff nurses in ECG monitoring and Interpretation after the competency program. ${ }^{4}$

The results of Table 7 showed that there was significant association between the knowledge of nursing students on ECG monitoring and interpretation and areas of work experience $\left(\chi^{2}=12.10, p=0.001\right)$ and years of work experience $\left(\chi^{2}=29.00, p<0.001\right)$. Also it is reported in Table 8 that there was significant association between the skill of nursing students in ECG interpretation and areas of work experience $\left(\chi^{2}=12.10, p=0.001\right)$ and years of work experience $\left(\chi^{2}=29.00, \mathrm{p}<0.001\right)$.

The study conducted by Lamb MJ and Henderson MC contradicts the findings of the present study which showed thatECG post-test scores obtained by the critical care staff nurses were found independent of their critical care experience, cardiac monitoring experience and their educational level. ${ }^{3}$

The present study findings contradicts the findings of the study conducted by Sheilini M in 2007 which showed that knowledge of critical care staff nurses who underwent the competency program on ECG 
monitoring and interpretation was independent of their areas of work $\left(\chi^{2}{ }_{(1)} 0.053, \mathrm{p}<0.05\right)$ and years of experience $\left(\chi_{(1)}^{2} 1.265, \mathrm{p}<0.05\right)$. Also the The skill of critical care staff nurses who underwent the competency program on ECG monitoring and interpretation was independent of their areas of work $\left(\chi_{(1)}^{2} 0.149, \mathrm{p}<0.05\right)$ and years of experience $\left(\chi^{2}{ }_{(1)} 0.741, \mathrm{p}<0.05\right){ }^{4}$

Table 9 show that there is significant relationship $(\rho=0.397, p=0.011)$ between the knowledge of nursing students in monitoring and interpreting ECG and skill in interpreting ECG. This finding supports the study conducted by McCloskey and McCain which showed that the years of total experience, was the best predictor of critical care skills $(r=0.25)$ and the Continuing education was significantly related $(r=0.18)$ to the Scale of Nursing Performance. ${ }^{6}$

IV. Tables

Table 1: Sample Characteristic Of Nursing Students In Terms Of Frequency And Percentage $(\mathrm{N}=\mathbf{4 0})$

\begin{tabular}{llll}
\hline Sl. No. & Sample Characteristics & $\begin{array}{l}\text { Frequency } \\
(\mathbf{f})\end{array}$ & $\begin{array}{l}\text { Percentage } \\
(\boldsymbol{\%})\end{array}$ \\
\hline 1. & Areas of work experience: & 31 & $77.5 \%$ \\
& ICUs & 9 & $22.5 \%$ \\
& Wards & & \\
2. & Years of experience: & 19 & $47.5 \%$ \\
& $<1$ year & 18 & $45 \%$ \\
& $>1-3$ years & 2 & $5 \%$ \\
& $>3-5$ years & 1 & $2.5 \%$ \\
& $>5-7$ years & & \\
\hline
\end{tabular}

Table 2: Frequency And Percentage Distribution Of Pretest And Posttest Knowledge Scores Of Nursing

\begin{tabular}{lllll} 
& \multicolumn{3}{c}{ StudentsN=40 } & \\
\hline Range of scores & Pretest & & Posttest \\
\cline { 2 - 5 } & $\begin{array}{l}\text { Frequency } \\
\text { (f) }\end{array}$ & Percentage (\%) & $\begin{array}{l}\text { Frequency } \\
\text { (f) }\end{array}$ & Percentage (\%) \\
\hline Poor (0-10) & 1 & & 0 & \\
Average (11-20) & 17 & $2.5 \%$ & 14 & 0 \\
Good (21-30) & 22 & $42.5 \%$ & 26 & $65 \%$ \\
\hline
\end{tabular}

Maximum possible score is 30 .

Table 3: Frequency And Percentage Distribution Of Pretest And Posttest Skill Scores Of Nursing Students N=40

\begin{tabular}{lllll}
\hline Range of scores & Pretest & Posttest & Percentage (\%) \\
\cline { 2 - 5 } & $\begin{array}{l}\text { Frequency } \\
\text { (f) }\end{array}$ & Percentage (\%) & $\begin{array}{l}\text { Frequency } \\
\text { (f) }\end{array}$ & \\
\hline & 23 & $57.5 \%$ & $0 \%$ & $0 \%$ \\
Poor (0-33) & 14 & $35 \%$ & 4 & $10 \%$ \\
Average (34-67) & 3 & $7.5 \%$ & 36 & $90 \%$ \\
Good (68-100) & & & & \\
\hline
\end{tabular}

Maximum possible score is 100 .

Table 4: Mean, Mean Difference, Standard Deviation Difference And ' $T$ ' Value Of Pretest And Posttest Knowledge Scores Of Nursing Student N=40

\begin{tabular}{|c|c|c|c|c|c|}
\hline \multirow[t]{2}{*}{ Area } & \multicolumn{2}{|r|}{ Mean } & \multirow[t]{2}{*}{ Mean Difference } & \multirow{2}{*}{$\begin{array}{c}\text { Standard } \\
\text { Deviation } \\
\text { Difference }\end{array}$} & \multirow[t]{2}{*}{ 't' value } \\
\hline & Pretest & Posttest & & & \\
\hline Knowledge & 2.52 & 2.65 & 0.13 & 0.071 & -1.302 \\
\hline
\end{tabular}

$\mathrm{T}_{(39)}=2.021, \mathrm{P}<0.05$ 
Effectiveness Of Educational Intervention On ECG Monitoring And Interpretation Among

Table 5: Mean, Mean Difference, Standard Deviation Difference And ' $T$ ' Value Of Pretest And Posttest Skill Scores Of Nursing Students $\mathrm{N}=40$

\begin{tabular}{|c|c|c|c|c|c|}
\hline Area & & Mean & $\begin{array}{c}\text { Mean } \\
\text { Difference }\end{array}$ & $\begin{array}{c}\text { Standard } \\
\text { Deviation } \\
\text { Difference } \\
\end{array}$ & ' $t$ ' value \\
\hline & Pretest & Posttest & & & \\
\hline Skill & 1.50 & 2.90 & 1.4 & 0.337 & -13.181 \\
\hline
\end{tabular}

$\mathrm{T}_{(39)}=2.021, \mathrm{P}<0.05$

Table 6: Areawise Analysis Of The Pretestandposttest Skill Scores Of Nursing Students

\begin{tabular}{llcccc}
\multicolumn{1}{c}{$\mathbf{N = 4 0}$} \\
\hline SI.No & \multicolumn{1}{c}{ Areas of skill } & \multicolumn{2}{c}{ Pretest } & \multicolumn{2}{c}{ Post test } \\
\cline { 2 - 7 } & & $\begin{array}{c}\text { Frequency } \\
(\mathbf{f})\end{array}$ & $\begin{array}{c}\text { Percentage } \\
(\boldsymbol{\%})\end{array}$ & $\begin{array}{c}\text { Frequency } \\
(\mathbf{f})\end{array}$ & $\begin{array}{c}\text { Percentage } \\
(\boldsymbol{\%})\end{array}$ \\
\hline 1 & & 6 & $15 \%$ & 22 & $55 \%$ \\
2 & Identifying components of ECG & 8 & $20 \%$ & 36 & $90 \%$ \\
3 & Interpretation of arrhythmias & 0 & 0 & 2 & $5 \%$ \\
\hline
\end{tabular}

Table 7: Chi-square values computed between the pretest knowledge scores of nursing students and selected variables

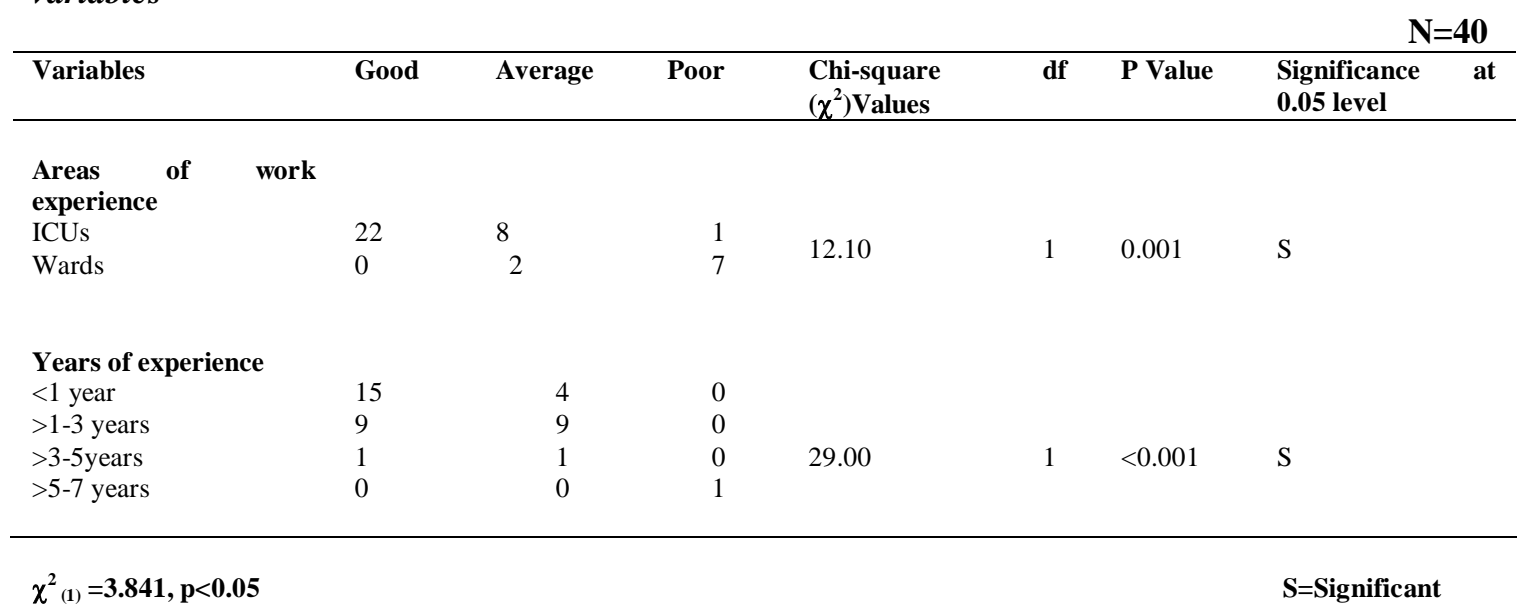

Table 8: Chi-square values computed between the pretest skill scores of nursing students and selected variables

\begin{tabular}{|c|c|c|c|c|c|c|c|}
\hline \multirow{2}{*}{ Variables } & \multirow[b]{2}{*}{ Good } & \multirow[b]{2}{*}{ Average } & \multirow[b]{2}{*}{ Poor } & \multirow[b]{2}{*}{$\begin{array}{l}\text { Chi-square } \\
\left(\chi^{2}\right) \text { Values }\end{array}$} & \multirow[b]{2}{*}{ df } & \multicolumn{2}{|r|}{$\mathrm{N}=40$} \\
\hline & & & & & & P Value & $\begin{array}{l}\text { Significance } \\
\text { 0.05 level }\end{array}$ \\
\hline \multicolumn{8}{|c|}{ Areas of work } \\
\hline ICUs & 3 & 9 & 19 & 12.10 & 1 & 0.001 & $\mathrm{~S}$ \\
\hline Wards & 0 & 4 & 5 & & & & \\
\hline \multicolumn{8}{|c|}{ Years of experience } \\
\hline$<1$ year & 3 & 9 & 7 & & & & \\
\hline$>1-3$ years & 0 & 4 & 14 & & & & \\
\hline$>3-5$ years & 0 & 1 & 1 & 29.00 & 1 & $<0.001$ & $\mathrm{~S}$ \\
\hline$>5-7$ years & 0 & 0 & 1 & & & & \\
\hline
\end{tabular}


Table 9: Relationship Between Knowledge And Skill Of Nursing Students In Ecg Monitoring And Interpretation $\mathrm{N}=\mathbf{4 0}$

\begin{tabular}{lcc}
\hline Variables & Pearson's $\boldsymbol{\rho}$ & P value \\
\hline Knowledge and Skill & 0.397 & $0.011^{*}$ \\
\hline
\end{tabular}

\section{Conclusion}

The result showed that there was no one with the poor knowledge prior to the intervention but still some improvement was seen in the knowledge after intervention but there was significant improvement in the skill of interpreting ECG $\left(\mathrm{t}_{(39)}=13.181, \mathrm{p}<0.05\right)$ after the intervention among nursing students. It proves that the teaching program conducted in this study worked as reinforcement for the students as the basics of ECG will be taught to them in their undergraduate level and also all were with clinical experience ranging between $<1$ year to $>5-7$ years. The study concluded saying thatElectrocardiographic monitoring is a cornerstone of the intensive care units. The quick response of the nurses to life threatening arrhythmias plays a central role in the prevention of sudden death in the hospital.

\section{References}

[1]. Eveloy V,Liu Y.etal. Developments in Ambulatory Electrocardiography.Biomedical Instrumentation and Technology ,40(3),2006,238.

[2]. Dianis NL. Cummings C.An interdisciplinary approach to process performance improvement.Journal of Nursing Care Quality, 12

[3]. (4), 1998,49-59.

[4]. Lamb MJ,Henderson MC.Comparison of two methods for teaching advanced arrhythmiasto nurses. Journal of Continuing Education in

[5]. Nursing,24(5),1993,221-226.

[6]. Sheilini M. Effectiveness of a competency program on ECG monitoring and interpretation for staff nurses working in critical care areas

[7]. and to determine the factors influencing their competency. Asian Journal of Cardiovascular Nursing,16(1),2008,2-7.

[8]. ClavarioP.Copello, F. etal.Use of an Arrhythmia simulator for the evaluation of nurses' knowledge and as a teaching tool.Competency

[9]. in Cardiology, 1995.

[10]. McCloskey JC, McCain B. Variables related to nurse performance. Image,20(4),1998,203-207. 